\title{
A COMPARATIVE ASSESSMENT OF DIFFERENT LOSS METHODS AVAILABLE IN MIKE HYDRO RIVER-UHM
}

\author{
Carina STRAPAZAN ${ }^{\mathbf{*}}$, Ionel HAIDU ${ }^{2}$ \& Ioan Aurel IRIMUS ${ }^{1}$ \\ ${ }^{1}$ Babeş-Bolyai University, Faculty of Geography, 5-7, Clinicilor Street, 400006, Cluj-Napoca, Romania, \\ *Corresponding author, e-mail: carinastrapazan@yahoo.ro; irimus@geografie.ubbcluj.ro \\ ${ }^{2}$ University of Lorraine, Laboratory LOTERR - EA 7304, Ile du Saulcy, 57045 Metz, France, e-mail: ionel.haidu@univ- \\ lorraine.fr
}

\begin{abstract}
Hydrologic modelling studies usually involve data series with a large temporal scale, especially in Romania, focusing on a long-term impact analysis. Nevertheless, event-based runoff models are essential tools for short-term purposes such as flash flood forecasting. Suitable methods or models must be considered in order to ensure the validity of such research based on parameter calibration to a particular area. Therefore, a comparative analysis of methods must be conducted first, in order to determine the optimal ones that can be used for future data prediction. The aim of the present study is to apply and validate the MIKE HYDRO River modeling system - the UHM module, through a comparative analysis of the SCS, Generalized SCS and Proportional Loss methods available, to a small-sized mountainous watershed, where no research has been conducted in this field. To this end, three spring rainfall events were chosen, but with different antecedent moisture conditions, in order to examine how well the chosen methods can reproduce the available observations in such circumstances. The SCS method yielded the highest quality performance, but the Proportional Loss method has also proven effective under these conditions.
\end{abstract}

Keywords: Mike Hydro River, Surface runoff, SCS method, Proportional Loss, Small basin

\section{INTRODUCTION}

Hydrological models have become an indispensable tool in the 21st century for decisionmaking regarding the management of water resources, flood forecasting, warning and hence, mitigating the effects associated with such phenomena (Irimus et al., 2015). Furthermore, hydrological modelling is a tool for empowering the water resources management specialists to identify potential threats, but also solutions regarding flood protection and the efficient use of financial resources for this sector. Hydrological methods that estimate runoff from a watershed and the time required for water to reach a downstream point, include both statistical analysis of discharge records and rainfall data which is the main input variable in rainfallrunoff models based on several equations and methods such as the unit hydrograph, the rational method, the kinematic wave and so on (Diez-Herrero et al., 2009).

Regarding the possibility of modelling the hydrological system response of one uniformly distributed unit excess rainfall in space, Șarpe \& Haidu
(2017) analyzed the temporal sampling conditions in numerical integration of hydrological systems time series. Thereby, hydrological modelling involves complex processes and such analyzes were all the more burdensome prior to the advanced software tools. Before the development of the computer technology in Romania and other countries, the surface runoff computation required laborious work and zonation maps with attributes of various parameters, reducing the importance and significance of the spatial variability of data inputs (Voda et al., 2018).

MIKE HYDRO River, developed by DHI (Danish Hydraulic Institute) is one of the most widely used 1D river modelling packages. It provides a variety of rainfall-runoff models, including the unit hydrograph method (UHM), which is the basic tool to estimate the surface runoff from an individual rainfall event. The modelling system is also a powerful tool for 1D hydrodynamic and hydraulic simulations in both natural and artificial channel networks (Gyori et al., 2016). The unit hydrograph provides an estimate of the excess rainfall and direct runoff from individual 
rainfall events and terrain characteristics. The losses to infiltration, surface storage and evaporation are expressed as proportional losses (the rational method), as fixed initial and constant losses, by the curve number (CN) method or by the SCS (Soil Conservation Service) Generalized one (DHI, 2017a).

Balan et al., (2016) conducted a runoff simulation study in the upper catchment of river Geru, using the Mike 11 modelling system with NAM and UHM modules, based on the rainfall event recorded on 11-13 September 2013. The four methods available in the UHM module were applied successively and the results were finally compared with those of the NAM module. The best results were achieved by the UHM-Constant loss method.

Ivanescu et al., (2014) used the MIKE 11UHM model to simulate runoff in the Argeșel river basin for two different rainfall events recorded in May 1995 and September 2005. The results of this study led to the conclusion that the calibrated and validated parameters best represent the runoff behaviour of the study area.

It is well known that a lot of factors have a great influence on the results, especially as regards the accuracy of the input data such as precipitation, temperature, discharge time series, etc.

Another study, conducted by Talchabhadel \& Shakya (2015) used the UHM module to determine the runoff hydrograph of the West Rapti River in Nepal, at four gauging stations within the watershed. The analysis is based on time series of maximum discharge. The UHM model calibration and validation for each subbasin were carried out by using discharge data covering the period from 1964 to 2008. The model was considered successfully validated because the relative error in peak discharge did not exceed $10 \%$.

While the existing literature provides various methods of estimating watershed's hydrological parameters (Haidu \& Strapazan, 2019), most rainfallrunoff studies using the Mike modelling software are based on continuous simulation with NAM. While NAM is a lumped model composed of a higher number of variables but which at the same time allows for automatic calibration (Liptay et al., 2018), the UHM model represents an alternative and it can also be used for runoff prediction in data-scarce areas (DHI, 2017b).

Event-based simulation is useful for short-term flood forecasting, while continuous RR modelling involves trend analysis and impacts of long-term management of the water resources. On this latter point, further watershed studies should be carried out, especially in Romania, focusing on the capability of Mike-UHM model to simulate runoff processes and even its application to real-time forecasting. The aim of this study therefore, is to provide a comparative analysis of different methods available in Mike Hydro River-UHM for calculating infiltration losses, in order to identify the best suited one for reproducing the overland flow in a small mountainous area, drained by the Teliu River, located in Central Romania. Another objective is to analyze, apply and validate this rainfall-runoff model for the study area.

Based on analyzing the available annual maximum discharges recorded at the gauge station between 2000-2018, three runoff events were selected to calibrate and validate the rainfall-runoff (RR) model, considering the streamflow and rainfall seasonality in this area (heavy rainfall events during April and May that triggered the annual peak flows). The water levels were among the highest on the historical 16-year record, exceeding the predetermined threshold for issuing warnings $(\mathrm{H}=100 \mathrm{~cm})$. However, the antecedent moisture conditions vary from event to event with lower values for the calibration one (AMC=1) and larger values associated with the ones selected for validation $(\mathrm{AMC}=3)$. Given the different runoff generating conditions and parameters, the runoff events were precisely chosen in order to see how the methods behave based on the values of these variables: a method that takes into account the AMC for estimating direct runoff if the initial conditions prior to the rainfall event are known, a method based on the initial abstractions and one that requires an appropriate runoff coefficient for the catchment.

Another viewpoint underlying the selection of the events for testing the model is that in order to obtain suitable estimates of the parameters needed to improve the simulation of extreme historical flood events which would require more detailed studies, assessing the RR model performance for moderate to high-magnitude flows is a necessary first step. Such runoff events can offer appropriate parameters describing the system behaviour and the conditions that push it close to a threshold during extreme rainfalls. This way, the hydrological model can be used for real-time forecasting of both moderate and extreme flow events with significant implications for river channel morphology or with devastating effects on the local communities and the agricultural sector.

\section{STUDY AREA}

The Teliu River collects its waters from the western slopes of the Intorsurii Mountains and is one of the major tributaries of the Tarlung River which is part of the upper Olt River (Fig. 1). It drains an area of approximately 36 sq.km mostly covered by pastures and broad-leaved forests. Considering the watershed's location, the typical climate of the area is 
characterized by cold and rainy periods and the maximum flow occurs generally during spring and autumn months, regularly exceeding $10 \mathrm{~m}^{3} / \mathrm{s}$.

The symmetrical shape of the drainage area and the small tributaries lead to a shorter time of flow concentration in the catchment during the wet season.

\section{DATA AND METHODS}

The 1D modelling approach using MIKE HYDRO River-UHM requires input data reflecting both the physical characteristics and hydrological processes of the watershed, regardless of the method chosen for simulation.

Generally, most digital computer models for calculating surface runoff apply to predefined calculation sections and drainage areas (Haidu et al., 2017), thus the catchment boundary and most of the parameters necessary for MIKE-UHM model's operation were extracted using both the GISArcHydro model based on a previous work by Strapazan \& Petruț (2017), and the HEC-GeoHMS module.

Three gauge-based precipitation and flow datasets were used as follows: a dataset which comprised information on the intensity of rainfall recorded during April, 2016 and two lower-resolution datasets recorded during April and May, 2012 which consist of 12-hour rainfall totals. Taking into account the resolution of collected data, as well as the subdaily time-scale model application, the information on rainfall intensity and duration for the last two above-mentioned events chosen for simulation was collected from Intorsura Buzaului weather station that is the closest to the basin centroid. Data were collected from Reliable Prognosis (RP5, 2019), processed and correlated with those retrieved from METEOMANZ (2019).

The three loss estimation methods were applied successively to the same rainfall data sets in order to simulate the surface runoff as follows:

\subsection{SCS Loss Method}

This method, developed by SCS (1972), is used to compute the surface runoff primarily on the basis of rainfall data and a $\mathrm{CN}$ parameter. The $\mathrm{CN}$ is used to express the runoff potential using the hydrologic soil groups, land cover and AMC information (Haidu et al., 2019) with a major influence on the runoff generation processes (Strapazan et al., 2019).

For each simulation time step within MIKE HYDRO River-UHM, the net rainfall volume represents the difference between the accumulated excess rainfall amount at the start and the end of the time step interval (DHI, 2017a).

This method involved calculations, which in this case were based on the European Digital Elevation

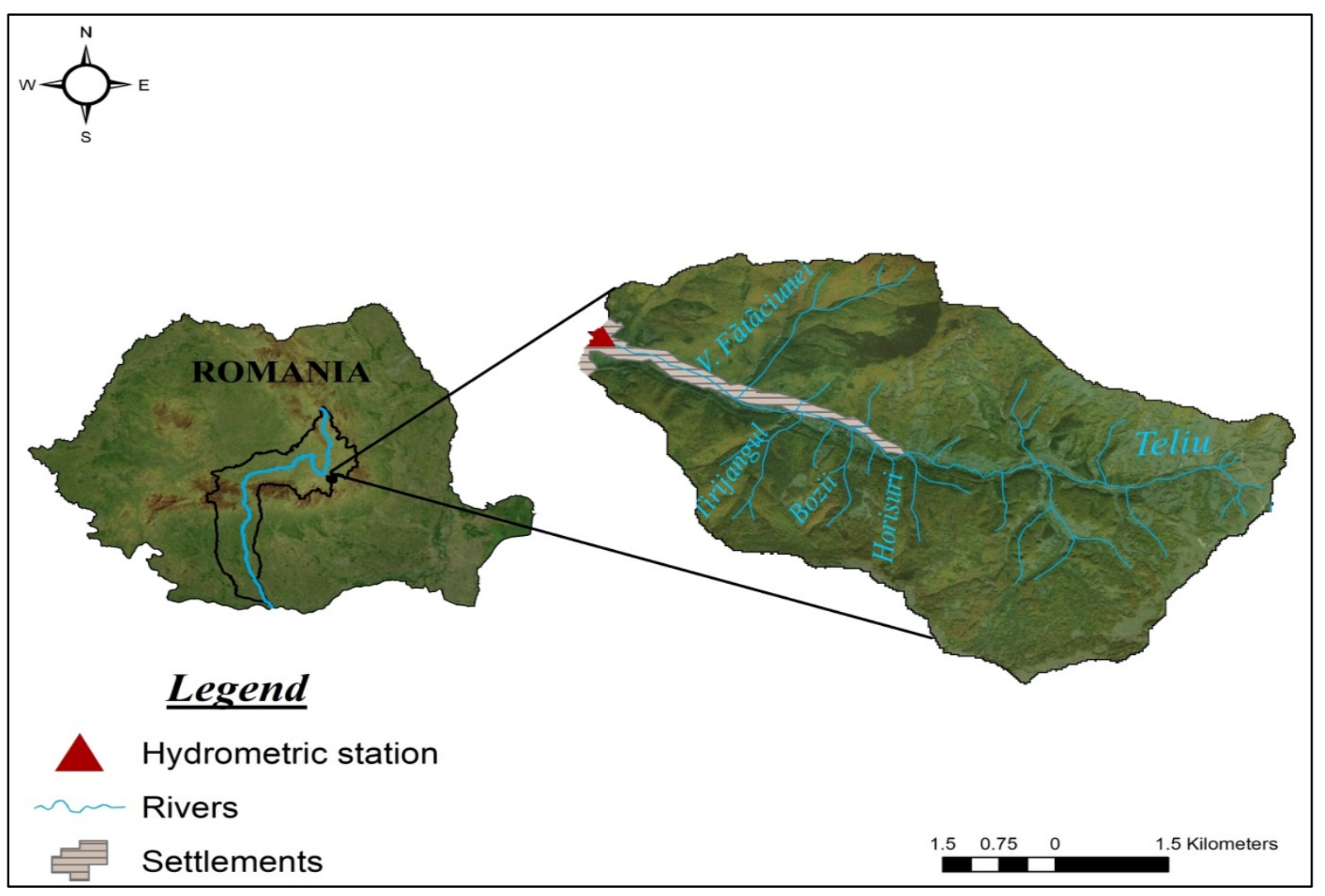

Figure 1. Teliu River, a tributary of the Upper Olt River Basin 
Model (EU-DEM) with a spatial resolution of $25 \mathrm{~m}$, the CLC 2012 (Corine Land Cover 2012) raster datasets and the digital 1:200000 soil map of Romania, thus obtaining the spatial distribution of $\mathrm{CN}$ values ranging from 34 to 85 within the study area (Fig. 2.a) as well as the required parameters for estimating the initial lag time according to the equation proposed by USDA-NRCS (2010).

\subsection{SCS Generalised Method}

This represents an alternative approach to the above-mentioned method for estimating the excess precipitation, also mainly depending on a weighted average of the $\mathrm{CN}$ for the watershed except that it does not consider the AMC, but implies a specific value of the initial abstraction depth (DHI, 2017a). The Ia (antecedent storage depth) value was determined in this case, by calibration processes.

\section{method)}

\subsection{Proportional Loss Method (the rational}

Losses are assumed to be a fixed proportion of the rainfall rate, the net precipitation being estimated based on a runoff coefficient value (DHI, 2017a):

$$
\mathrm{Pe}=\alpha^{*} A f^{*} \mathrm{Pr}
$$

\section{Where:}

Pe-excess rainfall $(\mathrm{m} / \mathrm{s})$;

$\alpha$-runoff coefficient;

Af-area adjustment factor;

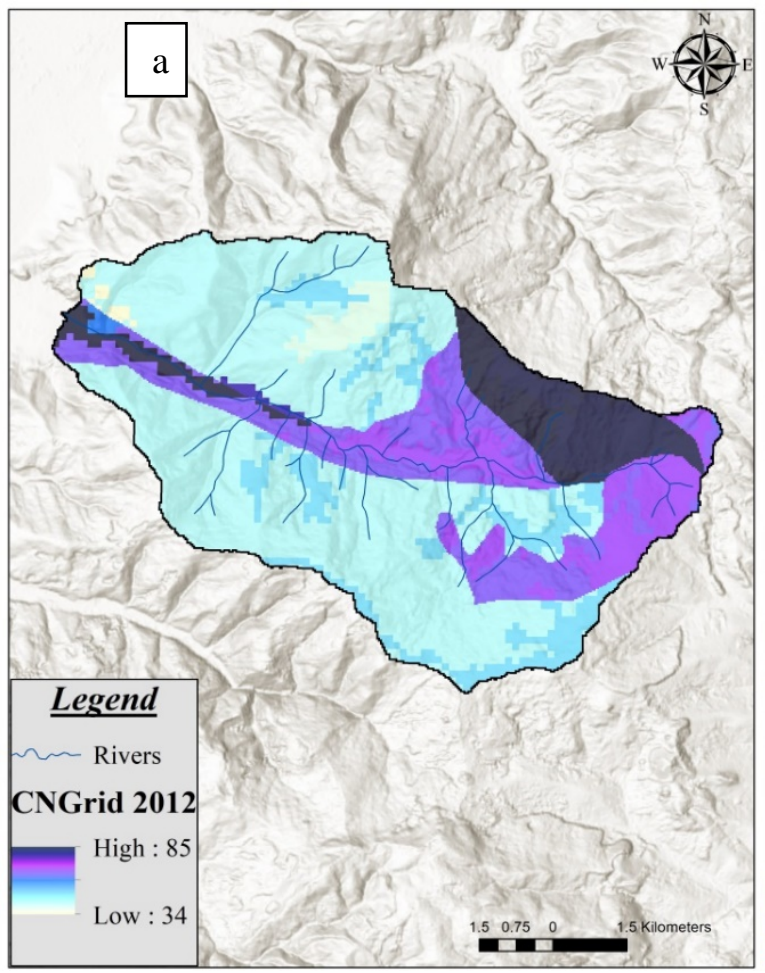

\section{Pr-rainfall rate $(\mathrm{m} / \mathrm{s})$.}

The estimation and the spatial distribution of the runoff coefficients were performed automatically using Frevert indices, within a GIS-based model developed by Crăciun (2011). The range of values varies from 0.12 to 0.45 for the drainage area (Fig. 2.b).

In order to assess the accuracy of simulations, numerical performance measures were used such as the mean absolute error (MAE) and the root mean squared error (RMSE), which are dimensional measures of comparison, as well as dimensionless goodness-of-fit measures such as the coefficient of determination $\left(\mathrm{R}^{2}\right)$, the Nash-Sutcliffe coefficient (E) and the index of agreement (d), (DHI, 2017b). The statistical indicators were automatically computed with the Time Series Comparator processing tool within MIKE Zero.

In addition to these indices, another index presented in the paper by Moriasi et al. (2007) was used, namely the RMSE-observations standard deviation ratio (RSR). This index was computed manually, separately as the ratio of the RMSE to the standard deviation of observed data:

$$
R S R=\frac{\left[\sqrt{\sum_{i=1}^{n}\left(Y_{i}^{\text {obs }}-Y_{i}^{\text {sim }}\right)^{2}}\right]}{\left[\sqrt{\sum_{i=1}^{n}\left(Y_{i}^{\text {obs }}-Y_{i}^{\text {mean }}\right)^{2}}\right]}
$$

Figure 2. The spatial distribution of CN (a) and Frevert coefficient (b) 
Where:

$Y_{i}^{o b s}$-measured time series data;

$Y_{i}^{\text {sim }}$-simulated time series data;

$Y^{\text {mean }}$-mean of measured time series data.

\section{RESULTS}

The simulations of the three runoff events were successively performed applying each of the above listed methods.

The flash flood event of interest for MIKE HYDRO River-UHM model calibration was the one triggered by the heavy rainfall from April, 2016, the maximum intensity values being recorded on the 11th of the month between $6 \mathrm{AM}$ and $9 \mathrm{AM}(27.4 \mathrm{~mm})$.

The first simulation was performed using the SCS Loss Method for a weighted average $\mathrm{CN}=54$ and $\mathrm{AMC}=1$ since the catchment was in a dry state prior to the rainfall event, because the total precipitation amount over the previous 5 days was less than 35.6 $\mathrm{mm}$ which is the threshold value suggested by SCS (1972) for an average moisture condition in the growing season. The watershed lag time was initially estimated to be close to 2 hours. The statistical analysis of the output data from the first simulation run indicated a poor agreement between simulated and measured data, considering the high MAE, RMSE and RSR values of 5.11, 6.64 and 1.53, the extremely low $\mathrm{R}^{2}$ and $\mathrm{d}$ values of 0.14 and 0.47 and especially the fact that $\mathrm{E}$ was less than 0 . Negative values of $E$ indicate that the mean value of the measured time series is a better predictor than the estimated values so that the model performance is unacceptable (Moriasi et al., 2007).

The index proposed by Willmott (1981), d, varies between 0 and 1, the upper bound indicating a perfect fit between measured and simulated values. A similar range and interpretation applies to $\mathrm{R}^{2}$ with values closer to 1 corresponding to a higher reliability (Legates \& McCabe, 1999).

Given the initial results, the gradually change of the $\mathrm{CN}$ was necessary along with the adjustment to normal moisture conditions (AMC =2). The first simulation results emphasize the uncertainties in the spatial distribution of rainfall and soil moisture. These uncertainties may be attributed to a higher spatial variability of precipitation in such a mountainous environment and a low rain gauge density.

The adjustment of the AMC without opting for a user defined lag time value, did not show a considerable improvement on the simulation results, the statistical indices showing relatively similar values to those obtained from the simulations carried out for AMC I. Therefore the SCS lag formula showed poor estimates of the basin lag time which is the reason why the parameter was determined by calibration, but without relying on random values. The measured data analysis led to the conclusion that a lag time value in the range 8 to 12 hours would be appropriate considering that about 12 hours have passed from the centroid of rainfall excess to the peak runoff. The calibrated values gave a surprisingly good agreement with the measured data, ending up coming to the conclusion that a lag time of 10 hours and CN value of 79 assigned to AMC II would be the most suitable.

The main input parameter of the SCS Generalised Method, Ia was determined by calibration, proportional to retention. The application of this method was carried out with values of Ia varying in the range from $20 \mathrm{~mm}$ (30\% of the storage potential) to $15 \mathrm{~mm}$ (23\% of the storage potential). The simulations were performed with the same parameter values determined with the first method ( $\mathrm{CN}=79$ and lag time $=10$ hours). The results indicated a good performance for the first attempt but an optimum value of 9 hours for the lag time was found by trial and error, the dimensionless coefficients taking values in the range 0.86 to 0.95 .

The Proportional Loss Method showed the best agreement between the measured and computed runoff values. Several simulations were performed starting from the weighted average value of the Frevert coefficient for the area $(0.36)$, and then gradually increasing it by up to $38 \%$. Although this was the best method, as compared to the others to capture the watershed response from the first model run, the value of 0.45 (an increase of 25\%) produced results with the lowest MAE, RMSE and RSR and the highest $\mathrm{R}^{2}$, E and $\mathrm{d}$.

In this case, however, a lag time of 12 hours was necessary, due to the greater differences between both hydrographs for a lag time of 9 to 10 hours, revealing a higher sensitivity of the method to this parameter variation.

The ranges of values for each statistic describing the relationship between the output and the measured data are given in Table 1.

Although the Proportional Loss method gave the best overall performance because the values are closer to the reference line, the SCS method reproduces better the hydrograph shape (Fig. 3). There is, accordingly, a positive linear relationship between measured and simulated values in all the cases, the Proportional Loss method showing the strongest one. The scatter of points indicates that at higher values the model tends to slightly overestimate 
Table 1. Statistics for different parameter values and loss methods used for calibration for the runoff event on April 2016

\begin{tabular}{|c|c|c|c|c|c|c|c|}
\hline $\begin{array}{l}\text { Infiltration } \\
\text { loss methods }\end{array}$ & Parameters & MAE & RMSE & RSR & $R^{2}$ & $E$ & $d$ \\
\hline \multirow{4}{*}{ SCS } & $\begin{array}{c}\mathrm{CN}=54-80 \\
\text { Initial } A M C=1 \\
\text { Derived lag } \\
\text { time }=1.19-2.32\end{array}$ & $\begin{array}{l}3.55- \\
5.11\end{array}$ & $\begin{array}{l}4.66- \\
6.64\end{array}$ & $\begin{array}{l}1.07- \\
1.53\end{array}$ & $\begin{array}{c}0.14- \\
0.41\end{array}$ & $<0.00$ & $0.47-0.70$ \\
\hline & $\begin{array}{c}\mathrm{CN}=54-80 \\
\text { AMC }=2 \\
\text { Derived lag } \\
\text { time }=1.15-2.32\end{array}$ & $\begin{array}{l}4.12- \\
4.76\end{array}$ & $\begin{array}{l}5.28- \\
7.90\end{array}$ & $\begin{array}{l}1.22- \\
1.82\end{array}$ & $\begin{array}{c}0.12- \\
0.47\end{array}$ & $\begin{array}{c}<0.00- \\
0.07\end{array}$ & $0.50-0.60$ \\
\hline & $\begin{array}{c}\mathrm{CN}=67-80 \\
\text { AMC }=2 \\
\text { User specified lag=8- } \\
12\end{array}$ & $\begin{array}{l}1.46- \\
3.41\end{array}$ & $\begin{array}{l}1.74- \\
4.23\end{array}$ & $\begin{array}{c}0.40- \\
0.97\end{array}$ & $\begin{array}{c}0.87- \\
0.94\end{array}$ & $\begin{array}{c}<0.00- \\
0.88\end{array}$ & $0.70-0.96$ \\
\hline & $\begin{array}{c}\text { Final: } \mathrm{CN}=79, \\
\text { AMC }=2, \text { User } \\
\text { specified lag=10 }\end{array}$ & 1.48 & 1.77 & 0.41 & 0.94 & 0.87 & 0.96 \\
\hline \multirow{3}{*}{$\begin{array}{c}\text { SCS } \\
\text { Generalised }\end{array}$} & $\begin{array}{c}\mathrm{CN}=79 \\
\text { Initial Ia=15-20 } \\
\text { User specified } \\
\text { lag=10 }\end{array}$ & $\begin{array}{l}1.86- \\
1.91\end{array}$ & $\begin{array}{l}0.18- \\
2.21\end{array}$ & $\begin{array}{c}0.04- \\
0.51\end{array}$ & $\begin{array}{l}0.87- \\
0.91\end{array}$ & $\begin{array}{l}0.84- \\
0.86\end{array}$ & 0.95 \\
\hline & $\begin{array}{c}\mathrm{CN}=79 \\
\text { Ia=15-20 } \\
\text { User specified lag=9 }\end{array}$ & $\begin{array}{c}1.81- \\
1.94 \\
\end{array}$ & $\begin{array}{l}2.11- \\
2.24\end{array}$ & $\begin{array}{c}0.49- \\
0.52 \\
\end{array}$ & $\begin{array}{c}0.90- \\
0.92 \\
\end{array}$ & 0.86 & 0.95 \\
\hline & $\begin{array}{c}\text { Final: } C N=79, \operatorname{Ia}=16 \text {, } \\
\text { User specified lag=9 }\end{array}$ & 1.89 & 2.2 & 0.51 & 0.92 & 0.86 & 0.95 \\
\hline \multirow{3}{*}{$\begin{array}{l}\text { Proportional } \\
\text { Loss }\end{array}$} & $\begin{array}{c}\alpha=0.36-0.50 \\
\text { User specified } \\
\quad \text { lag }=10\end{array}$ & $\begin{array}{c}1.78- \\
1.99\end{array}$ & $\begin{array}{l}2.09- \\
2.45\end{array}$ & $\begin{array}{c}0.48- \\
0.56\end{array}$ & 0.87 & $\begin{array}{l}0.75- \\
0.85\end{array}$ & 0.94-0.95 \\
\hline & $\begin{array}{c}\alpha=0.36-0.50 \\
\text { User specified } \\
\text { lag }=12\end{array}$ & $\begin{array}{c}1.18- \\
1.48\end{array}$ & $\begin{array}{l}1.42- \\
1.78 \\
\end{array}$ & $\begin{array}{c}0.33- \\
0.41 \\
\end{array}$ & 0.94 & $\begin{array}{c}0.81- \\
0.92 \\
\end{array}$ & 0.96-0.98 \\
\hline & $\begin{array}{c}\text { Final: } \alpha=0.45 \\
\text { User specified } \\
\text { lag }=12\end{array}$ & 1.18 & 1.42 & 0.33 & 0.94 & 0.92 & 0.98 \\
\hline
\end{tabular}

the actual flow, while the underestimation is mainly occurring for lower values. The SCS Generalised method seems to largely overestimate the higher flow values. The SCS and SCS Generalised methods overestimated the recorded peak discharge of 15.2 $\mathrm{m}^{3} / \mathrm{s}$, by $2 \%$. While the timing of the peak discharge for the first of the above-mentioned methods was very well reproduced, the hydrographs computed by the other two methods peaked about 1 hour before the measured one. The Proportional Loss method managed instead, to completely capture the peak discharge for this event.

The validation based on the previously calibrated parameters for each one of the methods and the runoff events from 2012 yielded acceptable results for SCS and Proportional Loss methods with minimum errors and the highest values for the dimensionless coefficients (Table 2).
Although the SCS Generalised method yielded the best outcomes for the April rainfall-runoff event, the errors were the highest for the one in May, the lowest $E$ value of 0.05 , slightly above the acceptable limit, suggesting that the method cannot be applied in this case.

Most of the results showed high d values for different methods and parameters. Although the errors clearly reveal a certain limit of acceptance for the method/model, the lowest $\mathrm{d}$ value was 0.47 for the first model run. Probably in this case, a threshold value approaching 1 would be a better indicative of an acceptable fit, rather than a near perfect one.

None of the methods managed to capture the peak discharge generated by the April, 2012 rainfall event but the SCS Generalised and Proportional Loss methods reveal a large discrepancy between the hydrograph peaks which is why the plots show a possible outlier. 

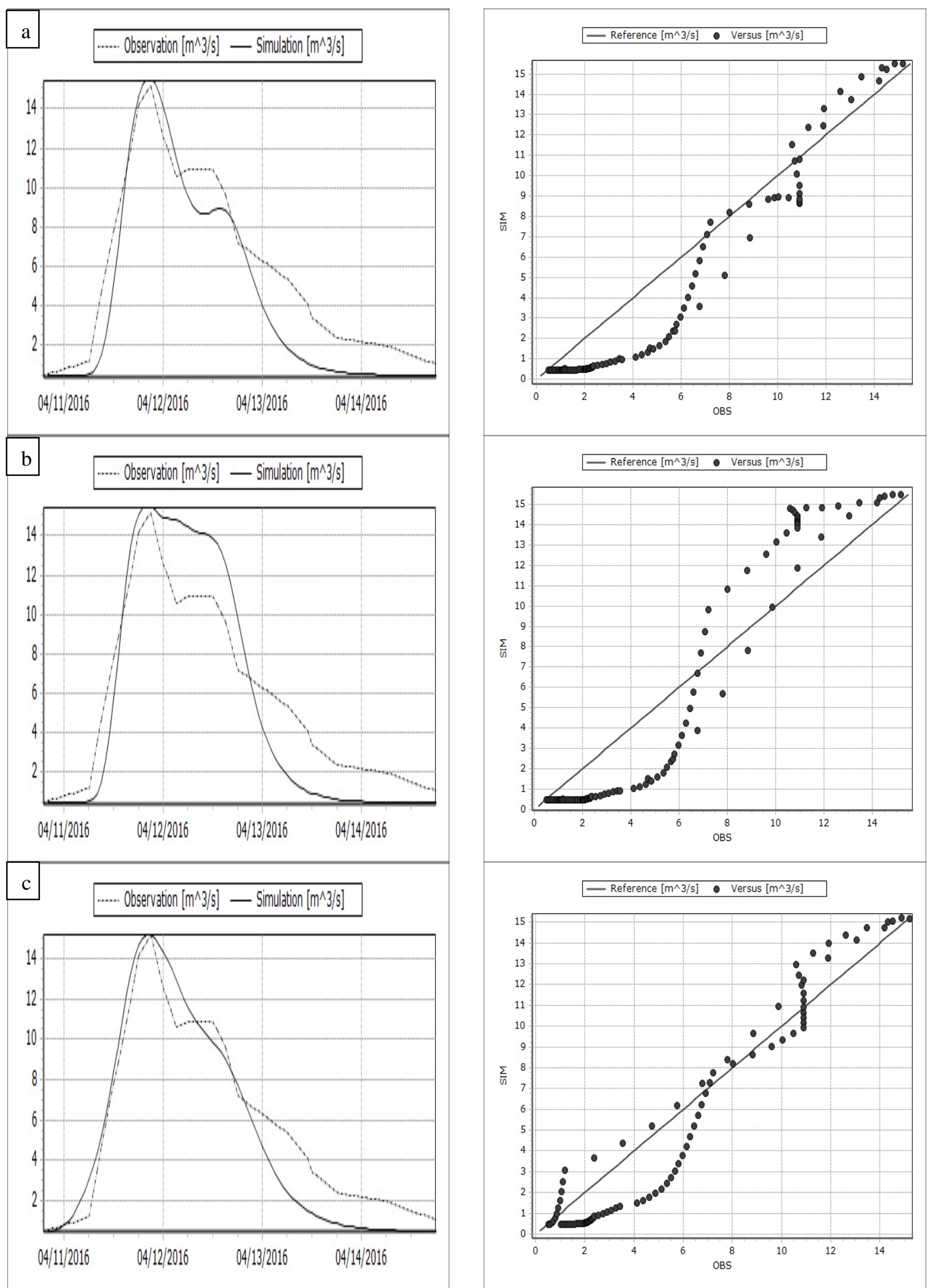

Figure 3. Comparison between the measured and estimated runoff hydrographs with the SCS (a), SCS Generalised (b) and Proportional Loss (c) methods for the April, 2016 event (left) and the corresponding scatterplots (right) 
Table 2. Validation and statistical evaluation results

\begin{tabular}{|c|c|c|c|c|c|c|c|}
\hline $\begin{array}{c}\text { Infiltration } \\
\text { loss methods }\end{array}$ & $\begin{array}{c}\text { Rainfall } \\
\text { event } \\
\text { date }\end{array}$ & MAE & RMSE & RSR & $\boldsymbol{R}^{\mathbf{2}}$ & $\boldsymbol{E}$ & $\boldsymbol{d}$ \\
\hline \multirow{3}{*}{ SCS } & Apr. 2012 & 0.69 & 0.93 & 0.50 & 0.89 & 0.85 & 0.95 \\
\cline { 2 - 8 } & May 2012 & 1.09 & 1.47 & 0.63 & 0.73 & 0.68 & 0.88 \\
\hline $\begin{array}{c}\text { SCS } \\
\text { Generalised }\end{array}$ & Apr. 2012 & 0.57 & 0.90 & 0.48 & 0.88 & 0.62 & 0.93 \\
\cline { 2 - 9 } & May 2012 & 1.20 & 1.58 & 0.91 & 0.38 & 0.05 & 0.76 \\
\hline $\begin{array}{c}\text { Proportional } \\
\text { Loss }\end{array}$ & Apr. 2012 & 0.81 & 1.21 & 0.28 & 0.68 & 0.61 & 0.90 \\
\cline { 2 - 9 } & May 2012 & 0.93 & 1.16 & 0.27 & 0.77 & 0.72 & 0.91 \\
\hline
\end{tabular}

The poor rain gauge distribution and density may have a significant impact on the simulation results, in this case. It is possible that a more intense local rainfall occurred in the upstream area of the basin which was not captured by the rain gauge. Nevertheless, just as in the case of the calibration event, the SCS method performed best for reproducing the hydrograph shape (Fig. 4). The measured peak discharge of $10.9 \mathrm{~m}^{3} / \mathrm{s}$ was underestimated by $16 \%$ with the SCS method, by $43 \%$ with SCS Generalised and by 35\% with the Proportional Loss one.

Both the Proportional Loss and the SCS methods provided accurate peak discharge time estimates, while there is a 1-hour difference for the other method.

Although the statistical indices showed that the Proportional Loss method yielded the best performance in reproducing the May, 2012 runoff event, the hydrograph shape and peak discharge were best reproduced also for this case by the SCS method with a mean error of approximately $1 \%$. The peak flow was slightly underestimated with a $15 \%$ error by Proportional Loss method. The SCS Generalised method underestimated the peak discharge by $38 \%$ and generated the most distinctive results with a large difference in the timing of peak flows (about 22 hours). Account must be taken on the fact that this method produced a double-peak hydrograph (Fig. 5) which didn't match the observations since the rainfall depth did not generate a bimodal runoff event. There is no doubt that the same lag time did not give very good results.

There's only 1 hour time difference between peak flows in the other two cases. It can therefore be said that the best results were provided by the SCS method with respect to the runoff volume, magnitude and timing of peak flows.

An interesting fact is that the best fit between the cumulative runoff volumes doesn't correspond to the calibration event, the cumulative volume of the flow being slightly underestimated, but to the May, 2012 validation event. The estimated cumulative runoff volume for the April, 2012 runoff event was higher than the observed one (Fig. 6).

\section{DISCUSSION}

The obtained results not only demonstrated that choosing the right runoff computation method plays a significant role in runoff modelling, but also that once the calibration parameters are established, and regarded as reliable, the model can be run for runoff events under different antecedent moisture conditions.

Four methods are available in the MIKE-UHM loss model, that differ from each other based on the required parameters and very few studies addressed their comparative analysis.

Beilicci \& Beilicci (2019) reported differences of up to $32 \%$ between peak flows resulting from the application of these methods to a single rainfall event in the Valea Mare watershed in Romania. This study focused only on three of the four methods and the resulting differences were greater, up to $60 \%$ when applied to several rainfall events in a much larger watershed. Such differences can have a major impact on future runoff predictions which is the reason why it is prudent to not only rely on one method or even model.

Balan et al., (2016) observed that the application of the SCS Generalised method yielded a hydrograph with four peaks, with a 26.5-hour difference in peak flow occurrence. The first peak was underestimated compared to the maximum recorded discharge, while the second one, which was the highest peak flow, overpredicted the measured value by $1.67 \%$. Similar findings were presented in this study for the May 2012 rainfall event, for which the SCS Generalised method yielded a double-peak hydrograph with a 22-hour difference between peak timings, but in this case, the method underestimated the peak flow.

The SCS-CN method proved to be an efficient tool for estimating direct runoff in such a small mountainous watershed, as also shown by other studies that applied the method to various watersheds in Romania such as the ones conducted by Haidu \& Strapazan, 2019, Strapazan \& Petruț, 2017, Gyori et al., 2016, Ivanescu et al., 2014, Gyori \& Haidu, 2011, and Crăciun et al., 2007. Nevertheless, the initial 

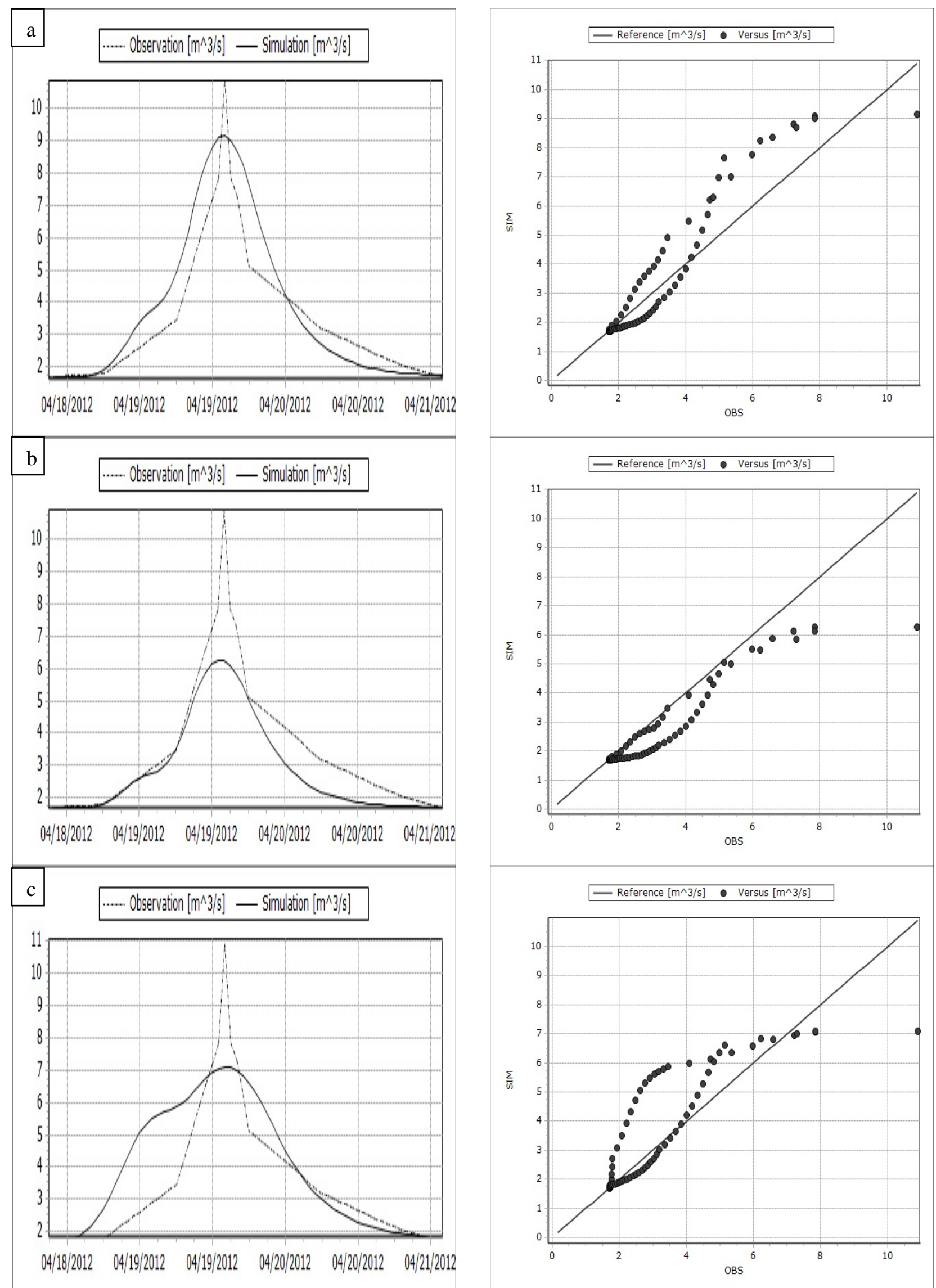

Figure 4. Comparison between the measured and estimated runoff hydrographs with the SCS (a), SCS Generalised (b) and Proportional Loss (c) methods for the April, 2012 event (left) and the corresponding scatterplots (right) 


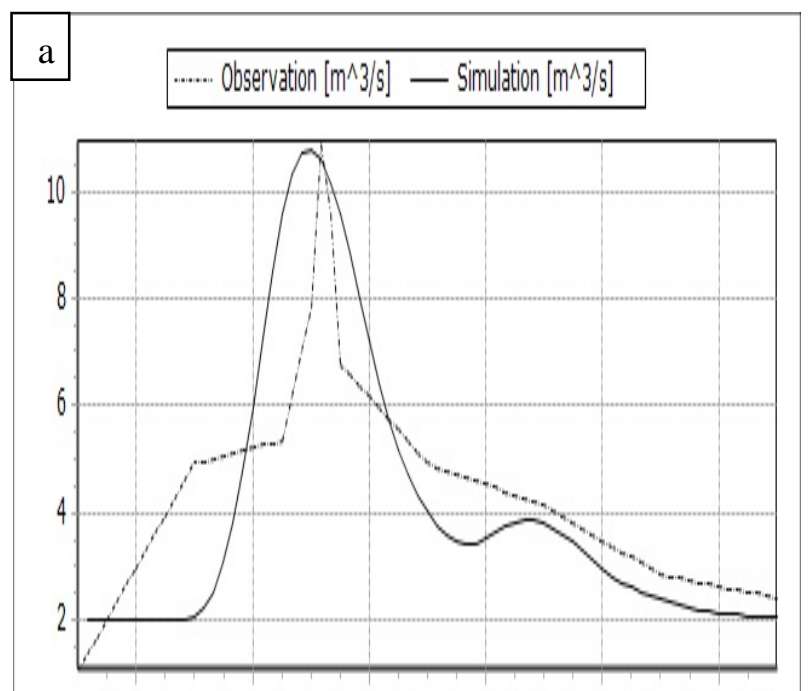

$05 / 29 / 2012 \quad 05 / 29 / 2012 \quad 05 / 30 / 2012 \quad 05 / 30 / 2012 \quad 05 / 31 / 2012 \quad 05 / 31 / 2012$

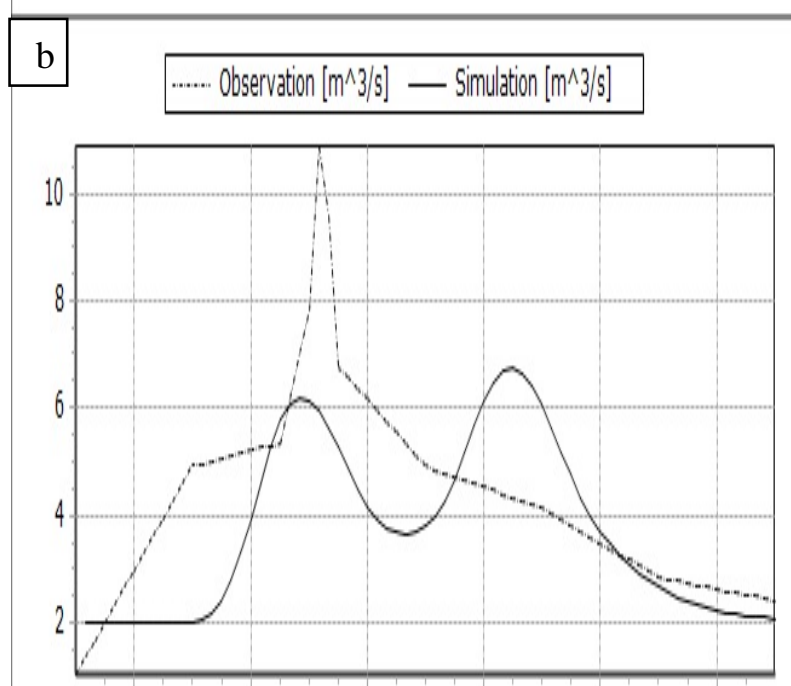

$05 / 20 / 2012 \quad 05 / 22 / 2012 \quad 05 / 30 / 2012 \quad 05 / 30 / 2012 \quad 05 / 31 / 2012 \quad 05 / 31 / 2012$
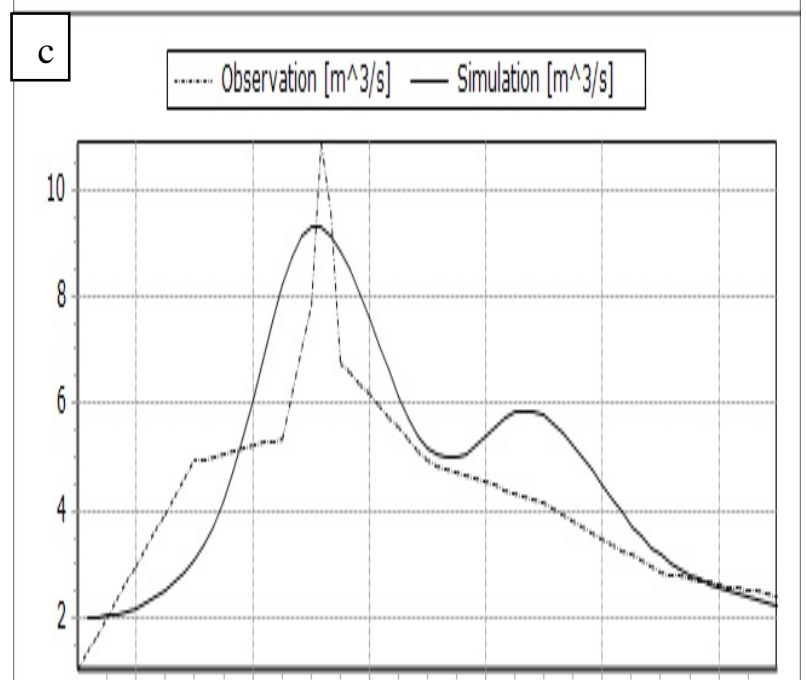

$05 / 29 / 2012 \quad 05 / 20 / 2012 \quad 05 / 30 / 2012 \quad 05 / 30 / 2012 \quad 05 / 31 / 2012 \quad 05 / 31 / 2012$
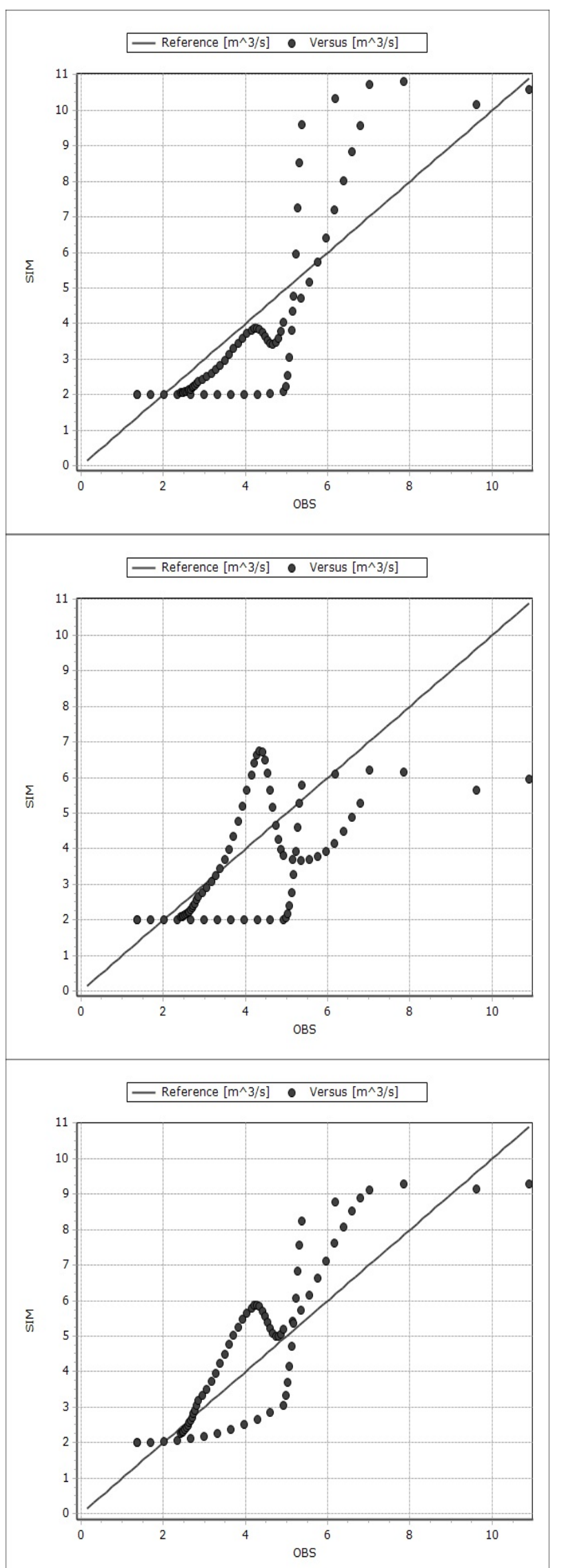

Figure 5. Comparison between the measured and estimated runoff hydrographs with the SCS (a), SCS Generalised (b) and Proportional Loss methods (c) for the May, 2012 event (left) and the corresponding scatterplots (right) 

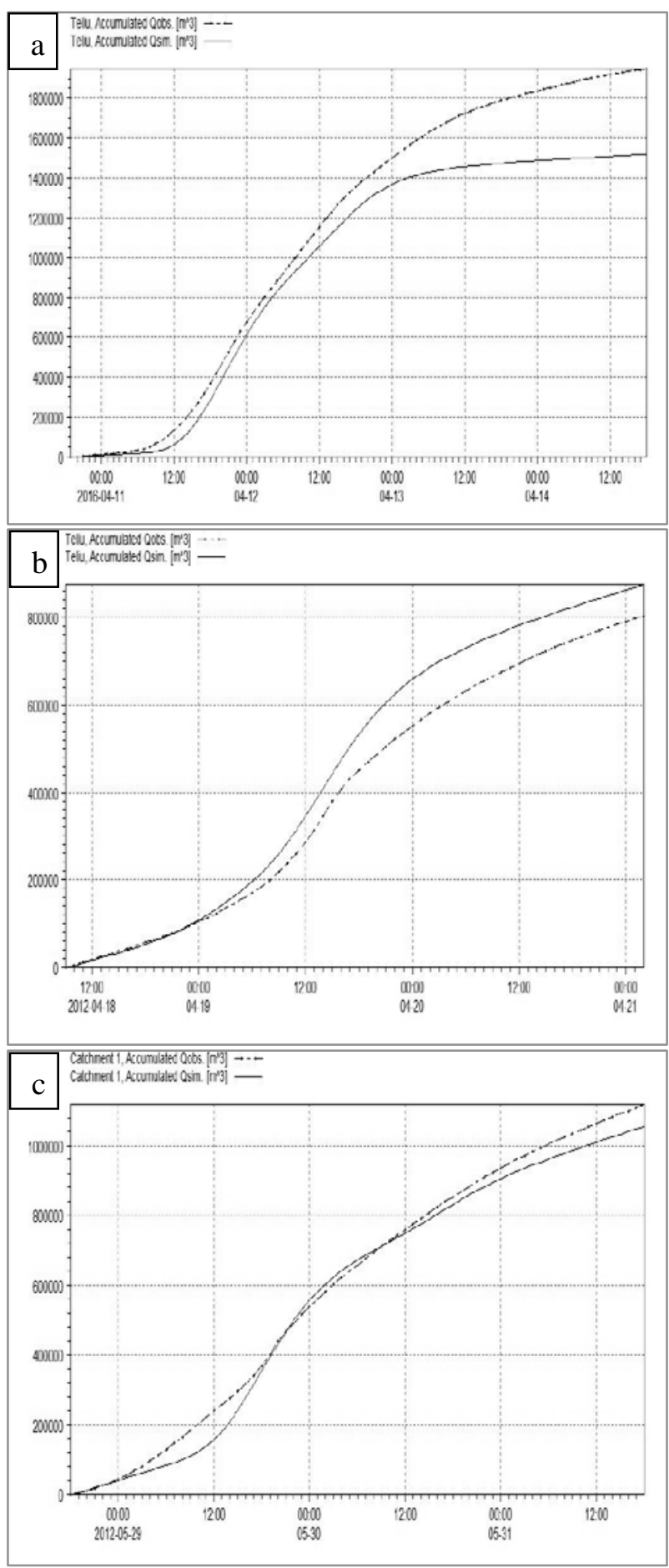

Figure 6. Comparison plots of observed and simulated cumulative flows with the SCS method for the April, 2016 (a), April, 2012 (b) and May, 2012 (c) events.

calibration based on the SCS lag time formula, yielded results that were in poor agreement with the measured values. The lag equation tended to underestimate the relationship between the corresponding travel time and the rainfall parameters, and hence the peak flow was overestimated, which is why the manual adjustment of the lag time was needed. In the case of small-sized catchments that require highly accurate prediction of the peak flow occurrence, the variables related to the rainfall intensity may need to be considered for estimating the watershed response time (Gericke \& Smithers, 2014). The formula may have given better results for a shortterm rainfall intensity, but in this case, the rainfall events were of lower intensity and longer duration, so future work addressing this issue may be needed.

The Proportional Loss method also provided reliable results, but for a slightly longer lag time compared to the SCS one, which is why it is difficult to establish an exact time of concentration to which the lag time is related.

\section{CONCLUSIONS}

This study presented a comparative analysis of some of the widely used methods for runoff estimation provided by the MIKE HYDRO River modeling system - the UHM module. When referring to the validation of a model or an equation that can be used for future forecasts, even if a positive outcome is achieved and the parameters are well established, it may be opportune to consider at least some of the many runoff modelling options provided by the scientific literature. Since not all models or methods are suitable for all geographic regions or environments, given the different climatic and terrain conditions, a comparative assessment can help the user establish the most convenient one that can be used in the future for the given area.

Although in this particular case the weakest results belonged to the SCS Generalised method, further study on extended series of events may be needed for a certain area or even more in order to provide a more in-depth assessment of its performance. The SCS and Proportional Loss methods proved to be highly effective for the study area, but the SCS one offered the advantage of reproducing the hydrograph shape and the peak flows with improved accuracy. The major feature of this method is that it accounts for the initial moisture conditions prior to the runoff event so that the model can be applied for different rainfall conditions, being highly capable of simulating the runoff dynamics.

In spite of the fact that the dimensionless coefficients values were close to 1 and the simulation errors were not large for this particular area and rainfall events, it is needless to say that further research on this method for other extreme precipitation events would be useful.

\section{Acknowledgements}

The authors would like to express their sincere gratitude to DHI Romania for providing the educational MIKE HYDRO River software license along with the 
training courses, documentation and constant support, without which this work would not have been possible.

Special thanks are also extended to the colleagues from the Olt Basinal Water Administration-Brasov Water Management System for their cooperation in providing data and information.

\section{REFERENCES}

Balan, I., Crenganiș, L. \& Corduneanu, F., 2016. Flood analysis using Mike 11 by DHI and ArcGIS. Case study - the flood in the upper catchment of river Geru, Galati county, Romania. RevCAD Journal of Geodesy and Cadastre, 20, 27-38.

Beilicci, E. \& Beilicci, R., 2019. Influence of Enlargement and Loss Model on the flood hydrograph in a small hydrographic basin. Scientific Bulletin of Politehnica University of Timişoara. Transactions on Hydrotechnics, 64, 2, 5-8.

Crăciun, A.I., 2011. Estimarea indirectă, cu ajutorul GIS, a umezelii solului în scopul modelării viiturilor pluviale. Aplicații în Munții Apuseni. Ph.D. Thesis, Cluj-Napoca, 278 pp.

Crăciun, A.I., Haidu, I. \& Bilaşco, Şt., 2007. The SCSCN model assisted by G.I.S.- alternative estimation of the hydric runoff in real time. Geographia Technica, 2, 1, 1-7.

DHI (Danish Hydraulic Institute), 2017a. MIKE 1D.DHI Simulation Engine for $1 D$ river and urban modeling. Reference Manual. Danish Hydraulic Institute, Horsholm, Denmark, 334 pp.

DHI (Danish Hydraulic Institute), 2017b. MIKE Zero. Preprocessing \& Postprocessing. User Guide. Danish Hydraulic Institute. Horsholm, Denmark, 380 pp.

Diez-Herrero, A., Laín-Huerta, L. \& Llorente-Isidro, M., 2009. A Handbook on Flood Hazard Mapping Methodologies. Geological Survey of Spain, Madrid, 190 pp.

Gericke, O.J. \& Smithers, J.C., 2014. Review of methods used to estimate catchment response time for the purpose of peak discharge estimation. Hydrological Sciences Journal, 59, 11, 1935-1971.

Gyori, M.M. \& Haidu, I., 2011. Unit Hydrograph generation for ungauged subwatersheds. Case study: The Monoroștia River, Arad County, Romania. Geographia Technica, 6, 2, 23-29.

Gyori, M.M., Haidu, I. \& Humbert, J., 2016. Deriving the floodplain in rural areas for high exceedance Probability Having Limited Data Source. Environmental Engineering and Management Journal, 15, 8, 1879-1887.

Haidu, I., Batelaan, O., Crăciun, A.I. \& Domnița, M., 2017. GIS module for the estimation of the hillslope torrential peak flow. Environmental Engineering and Management Journal, 16, 5, 1137-1144.

Haidu, I., Crăciun, A.I. \& Marian, R.A., 2019. Risk scenarios for flash-floods in the rural area generated by combined hazard, technologic and natural. Carpathian Journal of Earth and
Environmental Sciences, 14, 1, 181 - 190. DOI:10.26471/cjees/2019/014/070

Haidu, I. \& Strapazan, C., 2019. Flash flood prediction in small to medium-sized watersheds. Case study: Bistra River (Apuseni Mountains, Romania). Carpathian Journal of Earth and Environmental Sciences, 14, 2, $439 \quad-\quad 448$. DOI:10.26471/cjees/2019/014/093

Irimuș, I.A., Rus, M.I., Cioban, T.D., Bilașco, S., 2015. Quantitative Estimation of Annual Average Rate of Soil Erosion in the Almas Hydrographical Basin, Using USLE and GIS. In: 15th International Multidisciplinary Scientific GeoConference on Informatics, Geoinformatics and Remote Sensing, Conference Proceedings/Vol.II, Geodesy \& Mine Surveying, Cartography \& GIS, STEF92 Technology Ltd 51”Alexander Malinov”,Sofia, Bulgaria, 1071-1079.

Ivanescu, V., Mocanu, P., \& Sandu, M.A., 2014. Application of a hydrodynamic MIKE 11 Model for Argesel river. In: 14th International Multidisciplinary Scientific Geoconference. GeoConference on Water Resources.Forest, Marine and Ocean Ecosystem. Conference Proceedings, Albena, Bulgaria, 65-72.

Legates, R. D., McCabe, G. J., 1999. Evaluating the use of "goodness-of-fit" measures in hydrologic and hydroclimatic model validation. Water Resources Research, 35, 1, 233-241.

Liptay, Z.A., Czigany, S., Pirkhoffer, E. \& Klug, H., 2018. Hydrological modelling of small alpine watersheds with the NAM model. Carpathian Journal of Earth and Environmental Sciences, 13, 1, 235-248, DOI:10.26471/cjees/2018/013/021

METEOMANZ, 2019. SYNOP/BUFR observations. Data by hours. http://www.meteomanz.com/.

Moriasi, D.N., Arnold J.G., Van Liew, M.W., Bingner, R.L., Harmel, R.D. \& Veith, T.L., 2007. Model evaluation guidelines for systematic quantification of accuracy in watershed simulations. Transactions of the of the American Society of Agricultural and Biological Engineers, 50, 3, 885-900.

RP5, 2019. Reliable prognosis. https://rp5.ru/

Şarpe, C.A., \& Haidu, I., 2017. Temporal sampling conditions in numerical integration of hydrological systems time series. Geographia Technica, 12, 1, 82- 94.

SCS (Soil Conservation Service), 1972. National Engineering Handbook, Section 4: Hydrology. Department of Agriculture, Washington DC, 682 pp.

Strapazan C. \& Petruț M., 2017. Application of Arc Hydro and HEC-HMS model techniques for runoff simulation in the headwater areas of Covasna Watershed (Romania). Geographia Technica, 12, 1, 95-107.

Strapazan, C., Haidu, I. \& Kocsis, I., 2019. Assessing Land Use/Land Cover Change and its Impact on Surface Runoff in the Southern Part of the Tibleș and Rodnei Mountains. In: Air and Water - 
Components of the Environment Conference Proceedings, Cluj-Napoca, Romania, 225-236.

Talchabhadel, R., Shakya, N.M., Dahal, V. \& Eslamian, S., 2015. Rainfall Runoff Modelling for Flood Forecasting (A Case Study on West Rapti Watershed), Journal of Flood Engineering, 6, 1, 5361

USDA-NRCS (United States Department of AgricultureNatural Resources Conservation Service), 2010.
National Engineering Handbook. Time of concentration. 210-VI-NEH, Part 630, Chapter 15, U.S. Dept. of Agriculture, Washington D. C, 29 pp.

Voda, A.I., Şarpe, C.A. \& Voda, M., 2018. Methods of maximum discharge computation in ungauged river basins. Review of procedures in Romania. Geographia Technica, 13, 1, 130-137.

Willmott, C.J., 1981. On the validation of models. Physical Geography, 2, 184-194.

Received at: 10. 01. 2021

Revised at: 22. 02. 2021

Accepted for publication at: 25. 02. 2021

Published online at: 26. 02. 2021 